\title{
Penerapan Multiple Attribute Decision Making dengan Metode Simple Additive Weighting untuk Pemeringkatan Kerentanan Keamanan Website
}

\author{
RIZAL MUNADI ${ }^{1}$, MUKHROJI $^{2}$, SYAHRIAL ${ }^{3}$, ERNITA DEWI MEUTIA $^{4}$ \\ 1,2,3Program Studi Magister Teknik Elektro, Jurusan Teknik Elektro dan Komputer \\ ${ }^{4}$ Program Studi Teknik Elektro, Jurusan Teknik Elektro dan Komputer \\ Universitas Syiah Kuala, Banda Aceh \\ Email: rizal.munadi@unsyiah.ac.id
}

Received 30 April 2018 | Revised 20 Mei 2018 | Accepted 28 Mei 2018

\begin{abstract}
ABSTRAK
Pada universitas, website dibangun sebagai jendela informasi elektronik yang menyediakan informasi tentang pendidikan tinggi. Namun, adanya celah keamanan pada website berpotensi untuk dieksploitasi bagi kriminal teknologi informasi. Berdasarkan masalah ini, fokus penelitian ini ditekankan pada aspek keamanan. Dalam penelitian ini, perangkat lunak OWASP digunakan sebagai alat uji. Kemudian, evaluasi dan analisis dilakukan terhadap kerentanan website terhadap serangan. Akhirnya, dengan menggunakan teknik Multiple Attribute Decision Making dengan metode Simple Additive Weighting dilakukan proses pemeringkatan kerentanan terhadap lima website universitas negeri di Provinsi Aceh. Hasil pengujian menunjukkan bahwa potensi kerentanan yang paling tinggi terjadi pada Universitas-2 dengan nilai rata-rata kerentanan, 1,72. Kerentanan ini menunjukkan adanya celah keamanan ini yang harus segera diperbaiki segera agar informasi yang tersedia menjadi akurat.
\end{abstract}

Kata kunci: Website, OWASP, MADM, SAW, Kerentanan

\begin{abstract}
At the university, the website is built as a window of electronic information that provides information about higher education. However, the existence of security holes on the website has the potential to be exploited for criminal information technology. Based on this issue, the focus of this research is emphasized on the security aspect. In this study, OWASP software is used as a test tool. Then, the evaluation and analysis carried out against the vulnerability of the website against the attack. Finally, using the Multiple Attribute Decision Making technique using the Simple Additive Weighting method, vulnerability rating was made to five public university websites in Aceh Province. The test results show that the highest vulnerability potential occurs at University-2 with an average vulnerability score of 1.72. This vulnerability indicates a security hole that needs to be fixed immediately so that the information available becomes accurate.
\end{abstract}

Keywords: Website, OWASP, MADM, SAW, Vulnerability 
Penerapan Multiple Attribute Decision Making dengan Metode Simple Addition Weighting untuk Pemeringkatan Kerentanan Keamanan Website

\section{PENDAHULUAN}

Seiring dengan perkembangan teknologi informasi dan komunikasi dewasa ini, website merupakan sarana informasi penting yang dapat diakses publik secara bebas dan cepat. Penggunaan website sebagai jendela informasi elektronik juga menjadi bagian yang terintegrasi pada sistem informasi perguruan tinggi. Sebagai wadah informasi, suatu website tidak saja didesain sebaik mungkin, namun integritas keamanan website perlu menjadi perhatian yang serius. Teknologi pembuatan website, baik menggunakan content Management System (CMS) atau aplikasi lainnya, terus berkembang dengan berbagai fitur yang menarik. Kualitas website yang baik dengan penyajian informasi yang up-to-date, perlu diimbangai dengan keamanan. Namun berbagai teknik serangan keamanan terus bermunculan dan tindakan pencegahan perlu dilakukan agar integritas website tetap terjaga keberadaannya. Selain masalah keamanan, website juga menjadi wadah informasi yang dinilai dan dibuatkan dalam bentuk peringkat. Pemeringkatan suatu perguruan tinggi yang bersumberkan informasi yang tersajikan pada website, dilakukan oleh beberapa penilaian dengan kriteria dan indikator tertentu seperti Webometrics, UI Greenmetrics, Times Higher Education World University Ranking dan Academic Ranking of World Universities (ARWU) . Ini menunjukkan betapa pentingnya informasi yang disajikan pada suatu website dan layanan informasi yang disediakan.

Pada perguruan tinggi, selain untuk menyajikan informasi sebagai berita kepada publik dan civitas akademika, juga website diintegrasikan dengan berbagai sistem pangkalan data atau basis data (database). Bentuk basis data yang dibangun, disesuaikan dengan penamaan aplikasi tertentu pada website perguruan tinggi. Dalam era informasi dengan layanan melalui website, seorang mahasiswa tidak perlu datang langsung ke kampus untuk mendaftar ulang, melihat nilai matakuliah, mengisi Kartu Rencana Studi (KRS), melihat jadwal kuliah, atau bagi mahasiswa baru yang ingin mengetahui suatu jurusan atau program studi yang tersedia. Di dalam website kampus, terdapat banyak sekali basis data seperti data mahasiswa, data dosen, data pembayaran SPP, data jurusan dan program studi, serta data akademik lainnya. Namun disisi lain, adanya kelemahan dalam sistem informasi yang dibangun dapat menjadi celah keamanan bagi penyerang (attacker). Penyalahgunaan sangat mungkin dilakukan oleh pihak penyerang sehingga dapat melakukan aktivitas seperti mengambil data, menghapus data bahkan mengganti data penting website. Bila hal ini terjadi pada website kampus maka akan mengacaukan integritas sistem informasi dan dapat menimbulkan kerugian yang sangat besar.

Potensi terjadinya gangguan keamanan suatu website merupakan bagian dari ketidakpastian dan dapat saja terjadi kapan pun dan ini menarik banyak pihak untuk melakukan penelitian. Pada umumnya setelah aplikasi web selesai dibuat, sistem tersebut langsung diluncurkan untuk digunakan (Abdullah, dkk., 2013). Hal seperti ini lazim terjadi dan pemantauan terhadap keamanan suatu website, umumnya kurang menjadi perhatian yang serius dan dilakukan secara berkelanjutan. Hal seperti inilah yang memungkinkan terjadinya penyerangan. Teknik yang dilakukan oleh pihak yang melihat adanya potensi celah keamanan cukup beragam. Aplikasi teknik serangan yang digunakan untuk mendeteksi kerentanan juga berbeda-beda. Pada penelitian yang terkait dan telah dilakukan yang dengan menggunakan aplikasi w3af untuk pengujian website instansi pemerintah (studi kasus di Aceh) (Munadi dkk., 2013). Hasil yang diperoleh menunjukkan sekitar $50 \%$ website terdeteksi rentan terhadap SQL Injection. Dari serangan ini, persentase website yang berdampak dapat dipilah berdasarkan platform CMS yang digunakan dimana sekitar $87,5 \%$ menggunakan CMS Joomla. Untuk itu, diperlukan tindakan pencegahan dengan melibatkan peran administrator. Halaman akses pada website perlu diadakan validasi masukan dan memantau secara acak terhadap beberapa tindakan yang mungkin tidak wajar agar konten website admin tetap aman dari 
serangan SQL Injection. Tindakan pencegahan lainnya yang dapat dilakukan adalah melakukan pembaruan versi CMS secara berkala. Penelitian lain tentang kerentanan keamanan website perguruan tinggi swasta di Jakarta juga telah dilakukan (Mantra \& Alaydrus, 2015). Dalam penelitian ini dilakukan analisis bagaimana suatu informasi awal terkait target yang ditentukan, dapat diperoleh dengan teknik yang umum dilakukan seperti untuk pencarian informasi, baik menggunakan search engine maupun tool yang tersedia untuk information gathering atau intelligence gathering. Namun, tidak semua website memiliki kelemahan yang menyebabkan informasi yang rahasia dapat diambil dengan teknik SQL Injection. Selain itu, tidak semua file yang terdapat pada web address atau domain utama website dapat terserang dengan SQL Injection. Kelemahan atau kerentanan pada tiap website target tersebut tidak terkait dengan cara mendapatkan informasi hanya dengan teknik SQL Injection saja, namun masih dapat diterapkan dengan cara yang berbeda.

Tindakan lebih lanjut akibat dari adanya kelemahan sehingga integritas informasi suatu website dapat terganggu dan dapat ditindaklanjuti dengan pemantauan secara berkala. Data yang terkumpul akan menjadi data agregat untuk dikaji lebih lanjut. Berdasarkan data, peta kerentanan suatu website dapat dikaji dan dianalisis berdasarkan teknik serangan yang digunakan seperti SQL Injection, XSS dan lainnya. Hasil kajian ini kemudian secara agregat dapat dilakukan pemeringkatan. Salah satu sistem pendukung pengambilan keputusan untuk pemeringkatan dapat diterapkan metode Simple Additive Weighting (SAW) dalam penentuan prioritas. Pendekatan ini diambil agar efektivitas pengambilan keputusan yang dilakukan tercapai, dimana nilai setiap kriteria pada proses penentuan prioritas didasari metode SAW, sehingga proses penilaian akan lebih tepat. Dalam suatu hasil kajian dengan SAW ini menghasilkan alternatif terbaik dari sejumlah alternatif yang diberikan (Utama, 2013). Penelitian lain tentang penentuan sistem pengambil keputusan produk unggulan telah dilakukan (Nugroho \& Wulandari, 2016). Pada penelitian ini, metode yang digunakan dalam pengambilan keputusan penentuan produk unggulan adalah kombinasi metode Multiple Attribute Decision Making-Simple Additive Weighting (MADM-SAW). Pemilihan metode MADMSAW ini disebabkan pada kemampuannya untuk melakukan penilaian secara lebih tepat dibandingkan dengan model pengambilan keputusan yang lain. Hal ini didasari pada nilai kriteria dan bobot preferensi yang sudah ditentukan, kemudian dilanjutkan dengan proses pemeringkatan yang akan menyeleksi alternatif terbaik dari sejumlah alternatif yang tersedia.

Berdasarkan masalah celah keamanan website yang dikaji, analisis penelitian ini menghasilkan pemetaan potensi keamanan sehingga dapat diformulasi ke dalam pemeringkatan kerentanan keamanan website Perguruan Tinggi Negeri yang ada di Provinsi Aceh.

\subsection{Perguruan Tinggi}

Perguruan tinggi adalah satuan pendidikan penyelenggara pendidikan tinggi. Komponen penting suatu pendidikan tinggi terdiri dari peserta didik perguruan tinggi yang disebut mahasiswa, dan tenaga pendidik perguruan tinggi disebut dosen dan ditambah supporting staff yang membantu dalam kegiatan akademik dan administrasi. Berdasarkan pengelolaannya, perguruan tinggi dapat dibagi menjadi dua, yaitu Perguruan Tinggi Negeri (PTN) yang didanai dan diselenggarakan oleh pemerintah, dan Perguruan Tinggi Swasta (PTS) yang diselenggarakan oleh pihak swasta.

\subsubsection{Perguruan Tinggi Negeri di Aceh}

Aceh merupakan sebuah provinsi yang terletak di ujung pulau Sumatera, dan merupakan provinsi paling Barat di Indonesia. Sejak awal kemerdekaan, perhatian pemerintah daerah terhadap kemajuan masyarakat Aceh diarahkan salah satunya pada pembangunan sumber daya manusia melalui jalur pendidikan. Awal tahun 1960, di Provinsi Aceh telah dibangun Kota Pelajar dan Mahasiswa (Kopelma) di kawasan Darussalam, yaitu Universitas Syiah Kuala 
(Unsyiah) dan Institut Agama Islam Negeri (IAIN) Ar-Raniry, sebagai jantung hati rakyat Aceh. Dalam perkembangannya, saat ini di Provinsi Aceh telah memiliki beberapa Perguruan Tinggi Negeri (PTN) yang dikategorikan kedalam Universitas, Institut, Politeknik, dan Sekolah Tinggi. Daftar nama-nama PTN yang tersebar di Provinsi Aceh, ditunjukkan pada Tabel 1.

Tabel 1. Perguruan Tinggi Negeri di Aceh

\begin{tabular}{|c|c|c|}
\hline No. & Institusi Pendidikan Tinggi & Kota \\
\hline 1 & Universitas Syiah Kuala & Banda Aceh \\
\hline 2 & Universitas Islam Negeri Ar-Raniry & Banda Aceh \\
\hline 3 & Universitas Malikussaleh & Lhokseumawe \\
\hline 4 & Universitas Samudra & Langsa \\
\hline 5 & Universitas Teuku Umar & Meulaboh \\
\hline 6 & Institut Agama Islam Negeri Malikussaleh & Lhokseumawe \\
\hline 7 & Politeknik Negeri Lhokseumawe & Lhokseumawe \\
\hline 8 & Institut Agama Islam Negeri Zawiyah Cot Kala & Langsa \\
\hline 9 & STAIN Gajah Putih & Takengon \\
\hline 10 & STAIN Teungku Dirundeng & Meulaboh \\
\hline
\end{tabular}

Dalam kaitannya dalam penelitian ini, dari keseluruhan PTN yang ada di Aceh, ruang lingkup pada penelitian ini hanya diambil pada kategori universitas sebagai sampel. Dasar pertimbangan dipilihnya universitas dibandingkan jenis perguruan tinggi lainnya adalah skalabilitas akademik, dimana universitas mempunyai lebih banyak mahasiswa yang menekuni pendidikan yang tersebar pada berbagai program studi pada setiap fakultas. Selain itu, universitas mempunyai jumlah dosen dan tenaga kependidikan yang lebih banyak dibandingkan dengan kategori PTN lain.

\subsection{Multiple Attribute Decision Making}

Sistem Pendukung Keputusan (SPK) adalah bagian dari sistem informasi berbasis komputer termasuk sistem yang berbasis pengetahuan (manajemen pengetahuan) yang digunakan untuk mendukung pengambilan keputusan dalam suatu organisasi atau institusi. Juga dapat dikatakan sebagai sistem informasi berbasis komputer yang membantu user dalam mengatasi masalah dengan menggunakan data model. Namun, SPK tidak dimaksud untuk mengotomatisasikan pengambilan keputusan tetapi memberi peringkat interaktif yang memungkinkan pengambilan keputusan untuk melakukan berbagai analisis menggunakan model yang tersedia seperti Multiple Attribute Decision Making (MADM) (Sismoro \& Hartatik, 2015).

Multiple Attribute Decision Making merupakan suatu sistem pendukung pengambilan keputusan yang digunakan untuk mendapatkan jawaban atas suatu masalah di dalam ruang diskrit. Pada penggunaannya, proses MADM dapat dilakukan melalui beberapa tahap diantaranya penyusunan komponen kondisi, analisis serta sintesis sistem informasi. Ada beberapa metode yang dapat digunakan untuk menyelesaikan masalah MADM antara lain: Simple Additive Weighting (SAW), Weighting Product (WP), ELECTRE, Technique for Order Preference by Similarity to Ideal Solutions (TOPSIS), Analytic Hierarchy Process (AHP).

\subsection{Simple Additive Weighting}

Simple Additive Weighting (SAW) merupakan salah satu metode yang dapat digunakan untuk penentuan sistem pengambilan keputusan, kinerja metode ini adalah menentukan bobot pada setiap atributnya, kemudian pada tahap selanjutnya dilakukan pemeringkatan yang akan menyeleksi alternatif terbaik. Dalam metode SAW biasanya menggunakan konsep 
penjumlahan terbobot dari semua atribut di setiap alternatif (Sonata, 2015). Metode SAW sering juga dikenal dengan istilah metode penjumlahan terbobot. Konsep dasar metode SAW adalah mencari penjumlahan terbobot dari tingkat kinerja pada setiap alternatif pada semua atribut. Metode SAW membutuhkan proses normalisasi matriks keputusan $(X)$ ke dalam suatu skala yang dapat dibandingkan dengan semua peringkat alternatif yang ada. Berikut adalah rumus peringkat kinerja ternormalisasi, seperti yang ditunjukkan pada Persamaan 1.

$\frac{x_{i j}}{\max x_{i j}}$
$\frac{\operatorname{Rij}}{x_{i j} x_{i j}}$$\left\{\begin{array}{l}\text { Jika } j \text { adalah atribut keuntungan (benefit) } \\ \text { jika } j \text { adalah atribut biaya (cost) }\end{array}\right.$

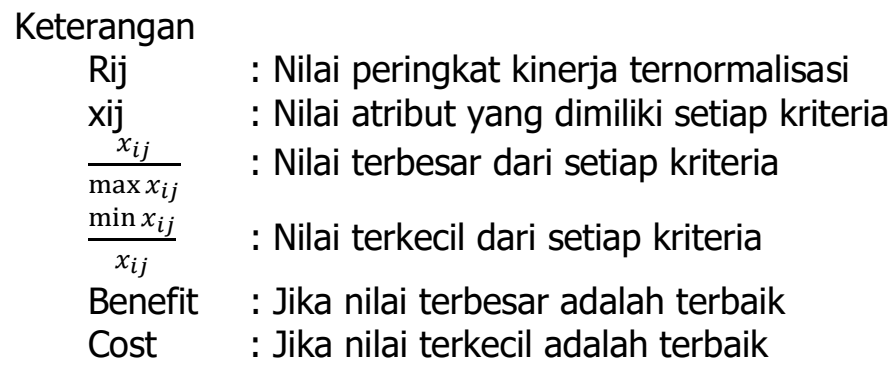

Dimana rij adalah peringkat kerja ternormalisasi dari alternatif, $A_{i}$ pada atribut, $C_{i}$. Dimana: $i=$ $1,2, \ldots, \mathrm{m}$ dan $\mathrm{j}=1,2, \ldots, \mathrm{n}$. Nilai preferensi untuk alternatif $\left(V_{i}\right)$ diberikan pada Persamaan 2 sebagai berikut:

$$
V_{i}=\sum_{j=1}^{n} w_{j} r_{i j}
$$

\section{Keterangan:}

$V_{i} \quad$ : Peringkat untuk setiap alternatif

$w_{j} \quad$ : Nilai bobot dari setiap kriteria

$r_{i j} \quad$ : Nilai peringkat kinerja ternormalisasi

\subsection{Keamanan Website}

Munculnya teknologi informasi berbasis internet telah memberikan banyak manfaat bagi kehidupan manusia di segala bidang. Wujud batas negara semakin kabur dengan mudahnya suatu informasi menyebar dan sebagian besar transaksi di dunia ini dilakukan secara online. Pertukaran informasi ini, tidak terlepas dari aplikasi website yang sudah menjadi bagian dari kegiatan sehari-hari setiap orang dengan menggunakan peramban tertentu, seperti Firefox, Chrome, Edge. Setiap informasi pada website menyediakan layanan otentikasi pengguna yang mengacu pada database. Jika kerahasiaan informasi dalam basis data terungkap keluar, maka tujuan melakukan transaksi online akan sangat berbahaya. Oleh karena itu, penyerang (attacker) dapat menggunakan kesempatan itu untuk mengambil username dan password pada layanan web. Target, salah satu pengecer potongan harga (discount retailer) terbesar kedua di Amerika Serikat (setelah Walmart), mengalami korban pelanggaran keamanan yang mempengaruhi lebih dari 70 juta pelanggan. Kejadian pencurian data kartu kredit dan kartu debit terjadi antara 27 November 2013 dan 18 Desember 2013. Dalam kejadian pada perusahaan Target, 40 juta nomor kartu kredit dan debit dan 70 juta catatan informasi pribadi 
dicuri (Plachkinova \& Maurer, 2018). Kejadian pada perusahaan Target merupakan salah satu tindak kejahatan yang terbesar terhadap penyalahgunaan akses oleh pihak yang tidak bertanggung jawab. Teknik serangan yang beragam dan salah satu serangan ini populer dikenali sebagai SQL Injection, suatu serangan yang mengeksploitasi basis data yang terhubung pada suatu aplikasi. Oleh karenanya harus dapat dideteksi dan dicegah (Abirami, 2015).

\subsection{Open Web Aplication Security Project}

Setiap pasar teknologi yang dinamis membutuhkan sumber informasi yang tidak bias mengenai praktik terbaik serta badan yang aktif mengadvokasi standar terbuka. Dalam kaitannya dengan keamanan aplikasi, salah satu dari kelompok tersebut adalah Open Web Aplication Security Project(OWASP). OWASP menawarkan sebuah aplikasi komunitas terbuka (Open Source)yang didedikasikan untuk organisasi yang memungkinkan untuk dilakukan pengembangan, dan juga pemeliharaan. Beberapa layanan yang disediakan OWASP secara terbuka antara lain too/dan standar keamanan aplikasi, buku tentang uji keamanan aplikasi, pengembangan kode, dan review kode keamanan, kendali keamanan dan pustaka standar, cabang lokal di seluruh dunia, riset terkini, konferensi lengkap diseluruh dunia, mailing list, dan banyak layanan lainnya yang dapat diakses melalui https://WWW.owasp.org. Berikut adalah tampilan OWASP yang ditampilkan seperti pada Gambar 1 (Open Web Aplication Security Project, 2010).

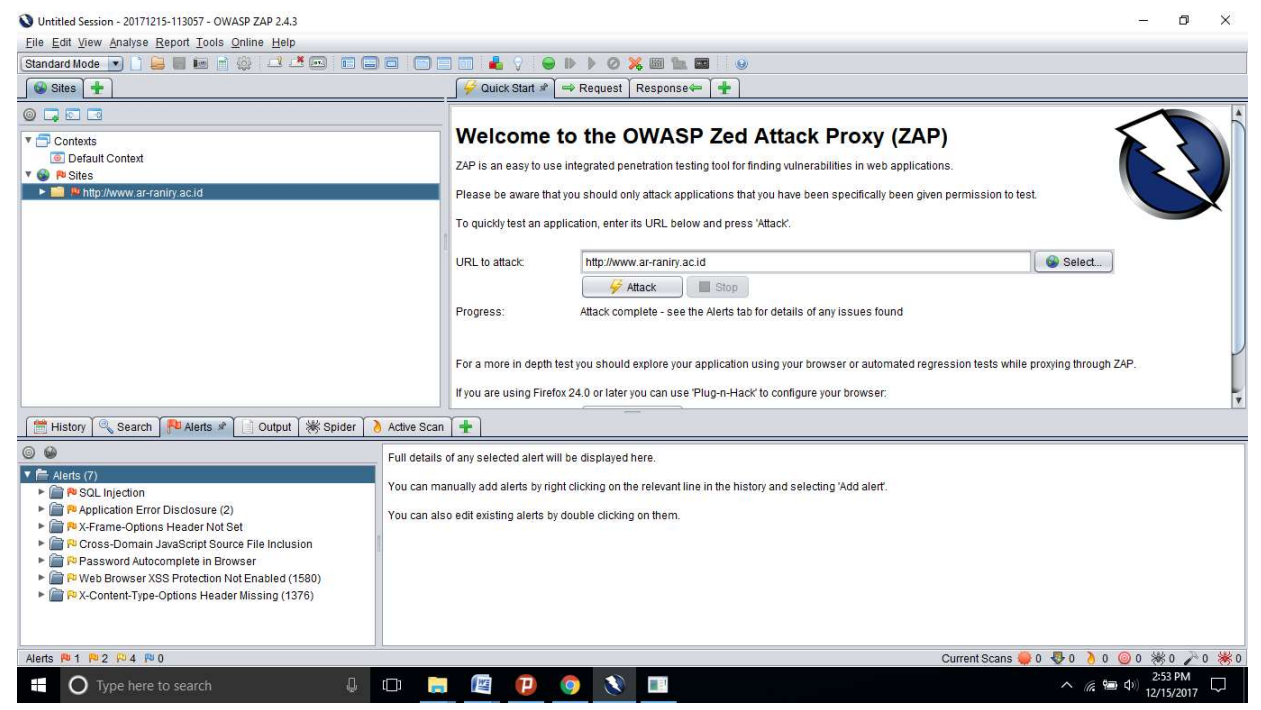

Gambar 1. Tampilan Aplikasi OWASP Saat Pengujian

Pada penelitian yang menggunakan OWAPS, dilakukan perbandingan beberapa aplikasi vulnerability scanner (Idrissi dkk., 2017). Dari hasil beberapa pengujian yang presisi dan tingkat pengukuran kerentanan disebutkan bahwa OWASP merupakan aplikasi paling baik dengan rata-rata pengujian adalah 95,67\%. Hasil ini jauh lebih tinggi dibandingkan w3af, BurpSuite, Acunetix, dan Wapiti.

\section{METODOLOGI PENELITIAN}

Pada penelitian ini dilakukan pengujian kerentanan keamanan website menggunakan OWASP, dan kemudian hasil survei kerentanan dievaluasi untuk menentukan peringkat keamanan terhadap kerentanan website dengan menerapkan metode Simple Additive Weighting (SAW). Terdapat 5 website universitas negeri yang ada di Provinsi Aceh yang dijadikan target uji 
dengan 4 parameter level kerentanan yang didefinisikan OWASP antara lain Informational, Low, Medium, dan High. Pengujian kerentanan website menggunakan software OWASP dilakukan sebanyak 5 kali untuk setiap website Universitas, dimana target yang diuji ada 5 website, maka total proses pengujian kerentanan adalah sebanyak 25 kali. Pengujian dilakukan secara bertahap, ada 5 siklus pengujian dalam pengujian ini, satu siklus pengujian adalah 5 website Universitas yang akan diuji, rentang waktu yang dihabiskan dalam 1 siklus pengujian berkisar antara 3 hari sampai 5 hari, tergantung pada kecepatan dan kestabilan jaringan internet. Sedangkan sistem pendukung pengambilan keputusan dengan MADM dalam proses pemeringkatan menggunakan metode SAW dilakukan setelah total siklus pengujian telah selesai. Hasil evaluasi uji kerentanan kemudian diproses melalui tahapan normalisasi matriks dan perkalian bobot untuk mendapatkan hasil pemeringkatan kerentanan website.

\subsection{Objek dan Alur Penelitian}

Objek yang dikaji pada penelitian ini adalah kerentanan website Universitas Negeri di Provinsi Aceh dan dilakukan pemeringkatan terhadap website yang paling rentan terhadap serangan. Alur penelitian ini memiliki beberapa tahapan seperti Gambar 2 di bawah ini.

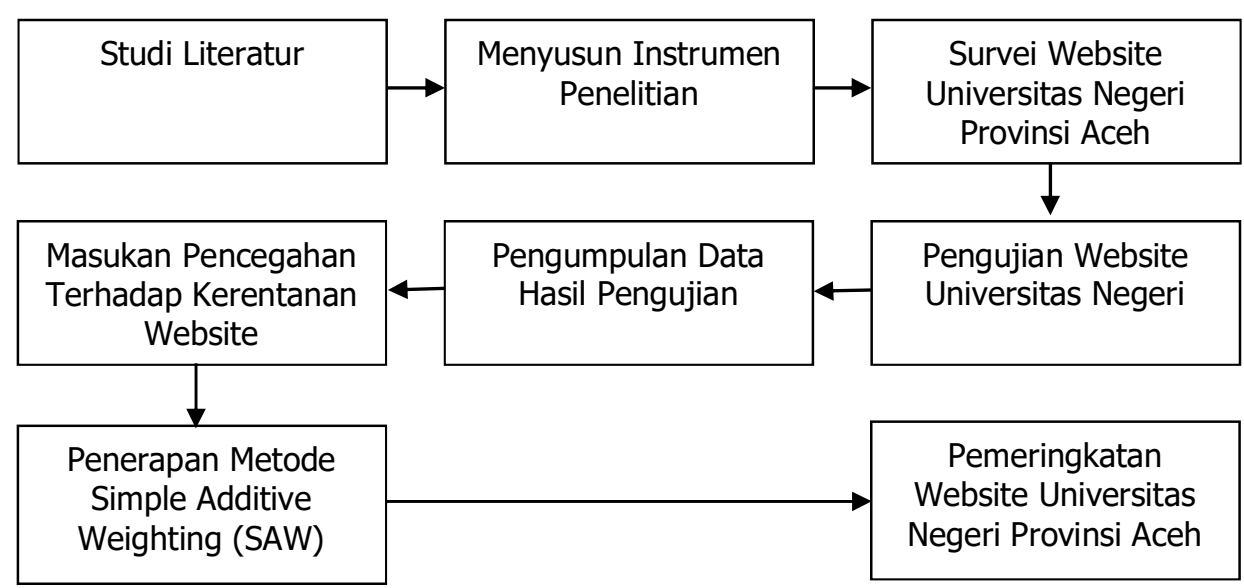

\section{Gambar 2. Diagram Alir Penelitian}

Tahapan awal dari penelitian ini adalah melakukan studi literatur sesuai dengan teori yang relevan dan hasil penelitian-penelitian sejenis yang pernah dilakukan. Kemudian dilakukan pengujian serangan terhadap 5 website universitas negeri di Provinsi Aceh. Dalam penelitian ini, akan dilakukan pengujian website menggunakan software OWASP untuk mendapatkan keakurasian nilai kerentanan masing-masing website. Tahapan berikutnya, data hasil uji menggunakan software OWASP diimplementasikan ke dalam Multiple Attribute Decision Making (MADM) dengan menggunakan metode Simple Additive Weighting (SAW) untuk menilai pemeringkatan kerentanan website dari universitas yang paling rentan terhadap serangan.

\section{HASIL DAN PEMBAHASAN}

\subsection{Data Universitas Negeri di Provinsi Aceh}

Berdasarkan sumber data yang disajikan pada pangkalan data perguruan tinggi negeri, https://forlap.ristekdikti.go.id/perguruantinggi, ada 5 universitas negeri di Provinsi Aceh. Secara geografis, letak setiap universitas ini tersebar: di ibu kota provinsi terdapat 2 universitas, kemudian masing-masing 1 universitas terletak di Aceh Timur, Aceh Utara dan Aceh Barat. Dengan menggunakan aplikasi Wappalyzer diperoleh data jenis Content Management System (CMS) yang digunakan oleh tiap universitas: 3 universitas yang 
menggunakan CMS Joom/a, 1 universitas menggunakan CMS Wordpress, dan 1 universitas lagi tidak menggunakan CMS. Berikut rincian datanya seperti yang ditampilkan pada Tabel 2.

Tabel 2. Data Universitas Negeri di Provinsi Aceh

\begin{tabular}{|c|c|c|}
\hline NO & PTN & CMS \\
\hline 1 & Universitas-1 & Joomla \\
\hline 2 & Universitas-2 & Non CMS \\
\hline 3 & Universitas-3 & Joomla \\
\hline 4 & Universitas-4 & Wordpress \\
\hline 5 & Universitas-5 & Joomla \\
\hline
\end{tabular}

\subsection{Evaluasi Penerapan Metode Simple Additive Weighting terhadap Website Universitas Negeri di Aceh}

Dari hasil pengujian kerentanan website yang dilakukan sebanyak 5 website dalam 1 siklus pengujian dengan menggunakan persamaan 1 . Nilai yang diperoleh kemudian dilakukan proses normalisasi. Nilai Vektor bobot dibagi dalam skala yang sama dengan interval 0,25 dengan rentang maksimumnya adalah 1 . Matriks keputusan, $X$, dibangun untuk kemudian dilakukan normalisasi dengan menggunakan persamaan 1. Alternatif diperoleh dengan menggunakan Persamaan 2. Berikut diuraikan prosesnya penyelesaiannya:

1. Langkah-langkah Penyelesaian

a) Vektor bobot: $W=[1,0,75,0,5,0,25]$

b) Matrik Keputusan $X$

$$
X=\left\{\begin{array}{lll}
4 & 2 & 0 \\
4 & 2 & 1 \\
2 & 1 & 0 \\
8 & 2 & 0 \\
5 & 2 & 0
\end{array}\right\}
$$

c) Normalisasi matriks $\mathrm{X}$ menggunakan Persamaan 1

\section{Alternatif A1}

4

$\mathrm{r} 11=\frac{}{\operatorname{Max}(2 ; 1 ; 3 ; 4 ; 2)}=0,5$

2

$\mathrm{r} 12=\overline{\operatorname{Max}(2 ; 2 ; 1 ; 2 ; 2)}=2$

0

r13

$\overline{\operatorname{Max}(0 ; 1 ; 0 ; 0 ; 0)}=0$
Alternatif A4

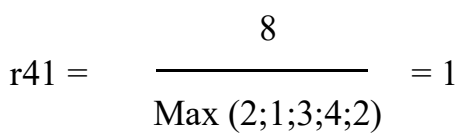

$\mathrm{r} 42=\frac{2}{\operatorname{Max}(2 ; 2 ; 1 ; 2 ; 2)}=1$

0
$\mathrm{r} 43=$
$\overline{\operatorname{Max}(0 ; 1 ; 0 ; 0 ; 0)}$ 


Alternatif A2
$\mathrm{r} 21=\frac{4}{\operatorname{Max}(2 ; 1 ; 3 ; 4 ; 2)}=0,5$
$\mathrm{r} 22=\frac{2}{\operatorname{Max}(2 ; 2 ; 1 ; 2 ; 2)}=1$
$\mathrm{r} 23=\frac{1}{\operatorname{Max}(0 ; 1 ; 0 ; 0 ; 0)}=1$
$\mathrm{r} 31=\frac{2}{\mathrm{Max}(2 ; 1 ; 3 ; 4 ; 2)}=0,25$
$\mathrm{r} 33=\frac{1}{\operatorname{Max}(0 ; 1 ; 0 ; 0 ; 0)}=0$
$\frac{\operatorname{Max}(2 ; 2 ; 1 ; 2 ; 2)}{0}=0,5$

Dari hasil perhitungan di atas maka didapat matriks ternomalisasi, $R$ sebagai berikut :

$$
R=\left\{\begin{array}{lll}
0,5 & 1 & 0 \\
0,5 & 1 & 1 \\
0,25 & 0,5 & 0 \\
1 & 1 & 0 \\
0,6 & 1 & 0
\end{array}\right\}
$$

d) Mencari alternatif terbaik menggunakan Persamaan 2

$$
\begin{aligned}
& V 1=(0,5 \times 0.5)+(0.75 \times 1)+(1 \times 0)=1 \\
& \text { V2 }=(\mathbf{0}, \mathbf{5} \times \mathbf{0 . 5})+(\mathbf{0 . 7 5 \times 1})+(\mathbf{1} \times \mathbf{1})=\mathbf{2} \\
& \text { V3 }=(0,5 \times 25)+(0.75 \times 0.5)+(1 \times 0)=0.5 \\
& \text { V4 }=(0,5 \times 1)+(0.75 \times 1)+(1 \times 0)=1.25 \\
& \text { V } 5=(0,5 \times 0.6)+(0.75 \times 1)+(1 \times 0)=1.1
\end{aligned}
$$

Dari hasil pengujian diatas, alternatif ke-2, V2 menunjukkan nilai tertinggi yang berarti alternatif ke-2 merupakan website paling rentan keamanannya dan alternatif ke-3, V3 diperoleh hasil dengan nilai terendah yang berarti alternatif ke-3 merupakan website yang 
paling aman dibandingkan semua alternatif pada pengujian ini. Hasil dari lima kali pengujian dari semua siklus pengujian dengan penerapan metode Simple Additive Weighting (SAW) akan disajikan pada Tabel 3 dan Tabel 4 berikut.

\section{Pengujian}

Data siklus pengujian pertama berupa hasil uji dari OWASP dirangkum ke dalam tabel kerentanan yang sudah diimplementasikan metode Simple Additive Weighting seperti yang ditunjukkan pada Tabel 3 berikut. Pada hasil pengujian tidak ditemukan kerentanan pada kategori informational.

Tabel 3. Data Matrik Pengujian

\begin{tabular}{|c|c|c|c|c|}
\hline Bobot $\left(\boldsymbol{w}_{\boldsymbol{j}}\right)$ & $\mathbf{0 , 2 5}$ & $\mathbf{0 , 5 0}$ & $\mathbf{0 , 7 5}$ & $\mathbf{1}$ \\
\hline Alternatif / Kriteria & Informational & Low & Medium & High \\
\hline Universitas-1 & 0 & 4 & 2 & 0 \\
\hline Universitas-2 & 0 & 4 & 2 & 1 \\
\hline Universitas-3 & 0 & 2 & 1 & 0 \\
\hline Universitas-4 & 0 & 8 & 2 & 0 \\
\hline Universitas-5 & 0 & 5 & 2 & 0 \\
\hline
\end{tabular}

Data matriks diproses melalui tahapan normalisasi dengan mengambil nilai pembagi paling besar pada kolom matriks $\left(\max x_{i j}\right.$ ) kemudian dibagi dengan matriks pada kolom tersebut $\left(x_{i j}\right)$ sehingga didapatkan hasil normalisasi matriks. Setelah mendapatkan nilai normalisasi matriks, kemudian dilakukan pemeringkatan $\left(V_{i}\right)$ kerentanan keamanan website dengan menggunakan Persamaan 2, berikut adalah hasil proses normalisasi matriks dan pemeringkatan yang ditampilkan pada Tabel 4.

Tabel 4. Data Normalisasi Matriks Pengujian

\begin{tabular}{|c|c|c|c|c|c|}
\hline \multicolumn{7}{|c|}{ Pembagi $\left(\max _{\boldsymbol{i} \boldsymbol{i j}}\right)$} & $\mathbf{0}$ & $\mathbf{8}$ & $\mathbf{2}$ & $\mathbf{1}$ & \multirow{2}{*}{ Hasil $\left(\boldsymbol{V}_{\boldsymbol{i}}\right)$} \\
\cline { 1 - 5 } & Normalisasi $\left(\boldsymbol{R}_{\boldsymbol{i j}}\right)$ \\
\hline Universitas-1 & 0 & 0,50 & 1,00 & 0 & 1,00 \\
\hline Universitas-2 & 0 & 0,50 & 1,00 & 1,00 & 2,00 \\
\hline Universitas-3 & 0 & 0,25 & 0,50 & 0 & 0,50 \\
\hline Universitas-4 & 0 & 1,00 & 1,00 & 0 & 1,25 \\
\hline Universitas-5 & 0 & 0,62 & 1,00 & 0 & 1,10 \\
\hline
\end{tabular}

Berdasarkan hasil pengujian pertama, penerapan metode SAW memberikan hasil website paling rentan terhadap serangan adalah website Universitas-2 dengan nilai 2 dan website paling aman adalah Universitas-3 dengan nilai kerentanan paling rendah yaitu 0,5 sedangkan website universitas lainnya berada dalam rentang aman di urutan ke-2 adalah Universitas-1 dengan nilai 1 , urutan ke-3 adalah Universitas-5 dengan nilai 1,1 dan yang ke-4 adalah Universitas-4 dengan nilai 1,25. Ini menunjukkan walau ada website yang dibangun dengan CMS yang sama, namun hasil kerentanan berbeda. 


\subsection{Rekapitulasi Keseluruhan Hasil Pengujian}

Rekapitulasi keseluruhan hasil uji pada penelitian ini terdapat lima bagian, yaitu pengujian pada siklus pengujian pertama sampai pengujian pada siklus pengujian ke-5. Hasil yang didapat dari rekapitulasi adalah pemeringkatan kerentanan seluruh pengujian, dan nilai ratarata dari hasil kerentanan siklus pengujian pertama sampai siklus pengujian ke-5 yang ditunjukkan pada Tabel 5. $P_{i r}$ merupakan Total Nilai Kerentanan Pengujian, dimana $\mathrm{i}=1,2,3$, 4,5 .

Tabel 5. Rekapitulasi Keseluruhan Hasil Uji

\begin{tabular}{|c|c|c|c|c|c|c|c|}
\hline \multirow{2}{*}{ Nama Universitas } & \multicolumn{5}{|c|}{ Pengujian Ke } & \multirow{2}{*}{ Total } & $\begin{array}{c}\text { Rata- } \\
\text { Rata }\end{array}$ \\
\cline { 2 - 6 } & $\mathbf{P 1}$ & $\mathbf{P 2}$ & $\mathbf{P 3}$ & $\mathbf{P 4}$ & $\mathbf{P 5}$ & & \\
\hline Universitas-1 & 1,00 & 0,75 & 1,70 & 0,68 & 0,97 & 5,10 & 1,02 \\
\hline Universitas-2 & 2,00 & 1,22 & 1,75 & 1,68 & 1,97 & 8,62 & 1,72 \\
\hline Universitas-3 & 0,50 & 1,61 & 0,85 & 1,34 & 1,86 & 6,16 & 1,23 \\
\hline Universitas-4 & 1,25 & 1,25 & 1,00 & 1,25 & 1,25 & 6,00 & 1,20 \\
\hline Universitas-5 & 1,10 & 0,89 & 1,25 & 0,82 & 1,14 & 5,20 & 1,04 \\
\hline
\end{tabular}

Berdasarkan rekapitulasi hasil uji dari keseluruhan siklus pengujian, didapati hasil total kerentanan: Universitas-1 mendapatkan total nilai kerentanan 5,10 dengan rata-rata nilai kerentanan 1,02. Evaluasi untuk universitas lainnya, Universitas-2 mendapatkan total nilai kerentanan 8,62 dengan rata-rata nilai kerentanan 1,72. Nilai yang diperoleh pada Universitas2 merupakan hasil yang paling besar nilai kerentanannya. Universitas-3 mendapatkan total nilai kerentanan 6,16 dengan rata-rata nilai kerentanan 1,23. Universitas-4 mendapatkan total nilai kerentanan 6 dengan rata-rata nilai kerentanan 1,20. Dan terakhir, Universitas-5 mendapatkan total nilai kerentanan 5,20 dengan rata-rata nilai kerentanan 1,04. Hasil total rata-rata kerentanan ditunjukkan pada Gambar 3.

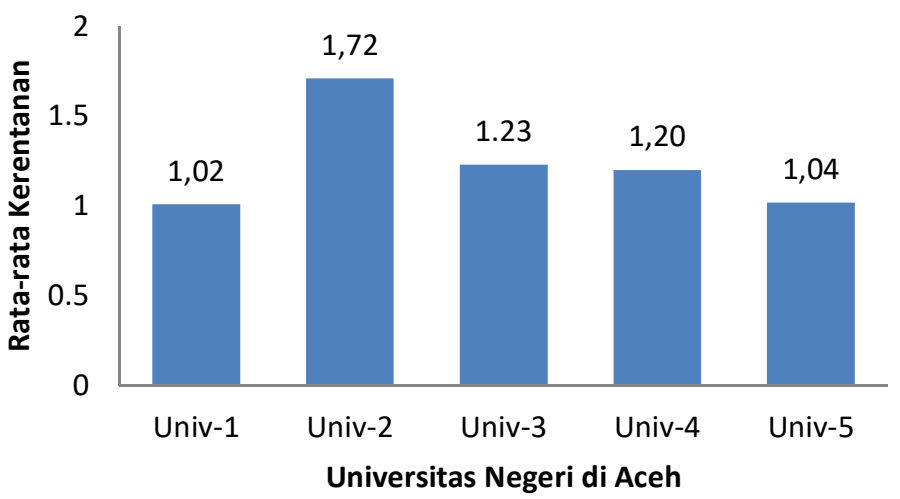

Gambar 3. Grafik Rata - Rata Kerentanan

Berdasarkan Gambar 3, terlihat jelas pemeringkatan kerentanan keamanan website universitas negeri di Aceh dengan menempatkan Universitas-1 dengan skor yang paling rendah atau paling kurang rentan dibandingkan universitas lainnya. Sebaliknya, website Universitas-2 
mendapatkan skor nilai kerentanan yang tertinggi dengan nilai 1,72. Hasil ini menunjukkan website Universitas-2 adalah yang paling rentan dibandingkan tingkat keamanan website universitas lainnya. Kerentanan ini mengindikasikan potensi adanya celah yang dapat disalahgunakan dan oleh karena itu perlu dilakukan pembenahan dan audit keamanan website. Salah satu solusinya untuk website Universitas-1 adalah penerapan salah satu CMS daripada mempertahankan website yang telah dibangun tanpa menggunakan Content Management System (CMS). Berdasarkan nilai kerentanan yang telah diperoleh, pada Tabel 6 disajikan indeks peringkat website universitas negeri di Aceh.

Tabel 6. Indeks Peringkat Kerentanan Universitas yang Diuji

\begin{tabular}{|c|c|c|c|}
\hline Nama Universitas & Total & Rata-Rata & Peringkat \\
\hline Universitas-1 & 5,10 & 1,02 & $\mathbf{1}$ \\
\hline Universitas-5 & 8,62 & 1,72 & $\mathbf{2}$ \\
\hline Universitas-4 & 6,16 & 1,23 & $\mathbf{3}$ \\
\hline Universitas-3 & 6,00 & 1,20 & $\mathbf{4}$ \\
\hline Universitas-2 & 5,20 & 1,04 & $\mathbf{5}$ \\
\hline
\end{tabular}

\section{KESIMPULAN}

Berdasarkan hasil pengujian dan analisis dalam penelitian ini, dapat disimpulkan:

1. Proses pengujian dengan menggunakan OWASP sebagai too/evaluasi kerentanan telah dilakukan terhadap lima website universitas negeri yang ada di Provinsi Aceh.

2. Penerapan MADM dengan metode SAW diperoleh peringkat yang paling rentan adalah website Universitas-2 sedangkan website Universitas-1 menjadi yang paling rendah kerentanan dari 5 website universitas yang diuji.

3. Hasil menunjukkan bahwa penggunaan CMS lebih baik dibandingkan website yang dibangun tanpa menggunakan CMS.

4. Penggunaan CMS untuk pembuatan website memberikan proteksi keamanan yang lebih baik dan audit keamanan perlu dilakukan secara berkala dengan melakukan penyesuaian dengan pembaruan versi CMS yang tersedia.

\section{DAFTAR RUJUKAN}

Abdullah, R. K., Zaini, A., \& Christyowidiasmoro. (2013). Simulasi Celah Keamanan Aplikasi Web dengan Kerangka Kerja OWASP, Jurnal Teknik POMITS, 2(1), 1-6.

Munadi, R., Fajri, T.S., Meutia, E.D., \& Elizar. (2013). Analysis of SQL injection attack in web service (a case study of website in Aceh province).Proc. of 2013 3rd Int. Conf. on Instrumentation, Communications, Information Technol., and Biomedical Engineering: 
Science and Technology for Improvement of Health, Safety, and Environment, ICICIBME 2013, (pp. 431-435).

Mantra, I. G. N., \& Alaydrus, M. (2015). Analisis Kerentanan Keamanan (VA) Web Perguruan Tinggi Swasta Jakarta. Prosiding SENATEK 2015, (pp. 1-6).

Utama, Y. (2013). Sistem Pendukung Keputusan Untuk Menentukan Prioritas Penanganan Perbaikan Jalan Menggunakan Metode Saw Berbasis Mobile Web. Jurnal Sistem Informasi (JSI), 5(1), 566-579.

Nugroho, S., \& Wulandari, F. T., (2016). Penerapan Metode MADM-SAW Dalam Penentuan Produk Kerajinan Unggulan Kabupaten Klaten. Jurnal SIMETRIS, $\nearrow(1), 163-168$.

Sismoro, H. (2013). Multiple Attribute Decision Making-Penggunaan Metode SAW dan WPM Dalam Pemilihan Proposal UMKM. Jurnal DASI, 14(1), 29-34.

Sonata, F. (2016). Implementasi Metode Simple Additive Weighting (SAW) Dengan Proses Fuzzifikasi Dalam Penilaian Kinerja Dosen. Jurnal Teknologi Informasi Dan Komunikasi, $5(2), 71-80$.

Plachkinova, M. \& Maurer, C. (2018). Teaching Case: Security Breach at Target. Journal of Information Systems Education, 29(1), 11-20.

Abirami, J.Devakunchari, R., \& Valliyammai, C. (2015). A Top Web Security Vulnerability SQL Injection Attack-Survey. The Seventh International Conference on Advanced Computing (ICOAC), (pp. 1-6).

Open Web Application Security Project (OWASP). (2018, Januari 23). OWASP Top Ten 2010. Retrieved from https://www.owasp.com

Idrissi, S.E., Berbiche, N., Guerouate, F., \& Shibi, M., (2017). Performance Evaluation of Web Application Security Scanners for Prevention and Protection against Vulnerabilities. International Journal of Applied Engineering Research, 12(21), 11068-11076. 